\title{
Tap and Reposition Youth (TRY): prestar apoio social e oportunidades de microcrédito e de poupanças a mulheres jovens em áreas com uma prevalência de VIH elevada
}

Annabel Erulkar

Population Council

Judith Bruce

Population Council

Erica Chong

Aleke Dondo

Jennefer Sebstad

See next page for additional authors

Follow this and additional works at: https://knowledgecommons.popcouncil.org/departments_sbsr-pgy

Part of the Demography, Population, and Ecology Commons, Family, Life Course, and Society

Commons, Gender and Sexuality Commons, and the International Public Health Commons

How does access to this work benefit you? Let us know!

\section{Recommended Citation}

Erulkar, Annabel, Judith Bruce, Erica Chong, Aleke Dondo, Jennefer Sebstad, James K. Matheka, Arjmand Banu Khan, and Anne Gathuku. 2006. "Tap and Reposition Youth (TRY): prestar apoio social e oportunidades de microcrédito e de poupanças a mulheres jovens em áreas com uma prevalência de VIH elevada," Promover transições para a idade adulta saudáveis, seguras e produtivas Sumário no. 15. New York: Population Council. 


\section{Authors}

Annabel Erulkar, Judith Bruce, Erica Chong, Aleke Dondo, Jennefer Sebstad, James K. Matheka, Arjmand Banu Khan, and Anne Gathuku 


\section{Tap and Reposition Youth (TRY): prestar apoio social e oportunidades de microcrédito e de poupanças a mulheres jovens em áreas com uma prevalência de VIH elevada}

\section{Elaborado por Annabel Erulkar, Judith Bruce, Erica Chong, Aleke Dondo, Jennefer Sebstad, James Matheka, Arjmand Banu Khan e Anne Gathuku}

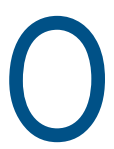

s adolescentes representam uma percentagem substancial e crescente de população que vive em bairros marginais nas grandes cidades africanas. Normalmente, nesses bairros pobres urbanos faltam infra-estruturas básicas e serviços governamentais, incluindo água, condições habitacionais adequadas, rede de esgotos, electricidade, serviços de saúde e autoridades policiais. A população jovem emigra para áreas urbanas em busca de oportunidades para estudar e trabalhar mas muitos são incapazes de atingir esses objectivos e em vez disso encontram-se em situações de elevado risco. As raparigas e mulheres jovens enfrentam, em particular, uma série de riscos contra a sua qualidade de vida, incluindo a infecção do VIH (devida em parte ao comércio sexual induzido pela pobreza), relações sexuais forçadas, violência doméstica, gravidez indesejada e aborto em condições pouco seguras.

Nairobi, no Quénia, acolhe uma dos maiores populações de bairros pobres na África subsariana. Dos 2 milhões de residentes da cidade, mais de metade vive nesses favelas, ocupando apenas $5 \%$ da área residencial da cidade (APHRC 2002). Os adolescentes que vivem nesses bairros, especialmente as jovens, interrompem os seus estudos e estão privadas dos ambientes potencialmente seguros das suas escolas e famílias e não têm oportunidades económicas seguras. Entre os jovens do sexo feminino com 15-17 anos de idade, $78 \%$ não estão a estudar e $58 \%$ não vivem sem nenhum dos pais. (Os números correspondentes para os jovens do sexo masculino representam $60 \%$ e $41 \%$ ). 0 desemprego é uma enorme preocupação para as jovens adolescentes e as circunstâncias desesperantes obriga-as a sobreviver conforme podem: $21 \%$ das jovens sexualmente activas entre os 15-19 anos de idade admitiram que têm relações sexuais em troca de dinheiro ou ofertas (Zulu et al. 2000). Essa vulnerabilidade acrescida reflecte-se nas taxas da infecção pelo $\mathrm{VIH}$ : entre os jovens com 15-24 anos de idade das áreas urbanas, cerca de $8 \%$ das raparigas e $3 \%$ dos rapazes estão infectados com o vírus (Central Bureau of Statistics et al. 2004).

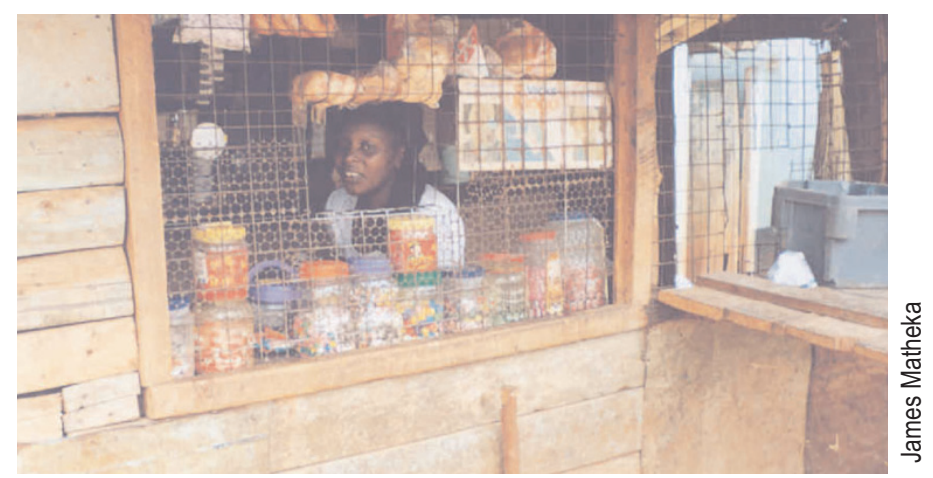

Em resposta a essas circunstâncias, o Population Council e a KRep Development Agency (a mais antiga e a maior instituição microfinanceira no Quénia) colaboraram no projecto e implementação de um programa chamado "Tap and Reposition Youth (TRY)". O objectivo era reduzir a vulnerabilidade dos adolescentes face a resultados adversos sociais e de saúde reprodutiva, incluindo a infecção do $\mathrm{VIH}$, melhorando as alternativas aos seus meios de vida. Os programas de microcrédito (o fornecimento de serviços financeiros que incluem o crédito, poupança, seguros e transferências de dinheiro para agregados familiares com baixos rendimentos) surgiram nos anos 70 no Sul da Ásia - nomeadamente no Bangladesh e na Índia, onde instituições como o Grameen Bank desenvolveram os seus programas nas áreas rurais, prestando serviços principalmente a mulheres casadas entre os seus 20 e 40 anos que tinham terminado ou quase terminado a sua gravidez. Essa estabilidade a nível habitacional e social das mulheres permitiu-lhes manter durante muitos anos a sua afiliação no mesmo grupo de auto-ajuda dos seus pares e apoiou-as na edificação passo a passo dos seus rendimentos financeiros. Utilizando principalmente o modelo do microcrédito desenvolvido na Ásia durante as últimas duas décadas, a K-Rep tem prestado serviços a clientes com baixos rendimentos no Quénia. O programa TRY, que visou as jovens adolescentes e as mulheres jovens com idades entre os 16-22 das áreas urbanas que 
abandonaram os estudos, foi a primeira iniciativa da K-Rep unicamente dirigida a raparigas adolescentes e mulheres jovens. Dada a pouca semelhança entre as circunstâncias dessas jovens com as das mulheres casadas em locais rurais, foi necessária uma abordagem experimental e de pensamento inovador que adaptasse 0 modelo do microcrédito a fim de ir ao encontro das suas necessidades. O modelo TRY foi evoluindo ao longo da duração do programa, passando de um modelo minimalista de poupanças e crédito para um que também oferecia aos seus clientes apoio social e uma opção de poupança voluntária individual.

\section{Primeira fase - Centrada na formação de grupos e no crédito} (1998-2000)

A fase piloto do TRY durou de 1998 a 2000 e chegou a mais de 100 raparigas. Grupos de auto-ajuda, cada um com cerca de 25

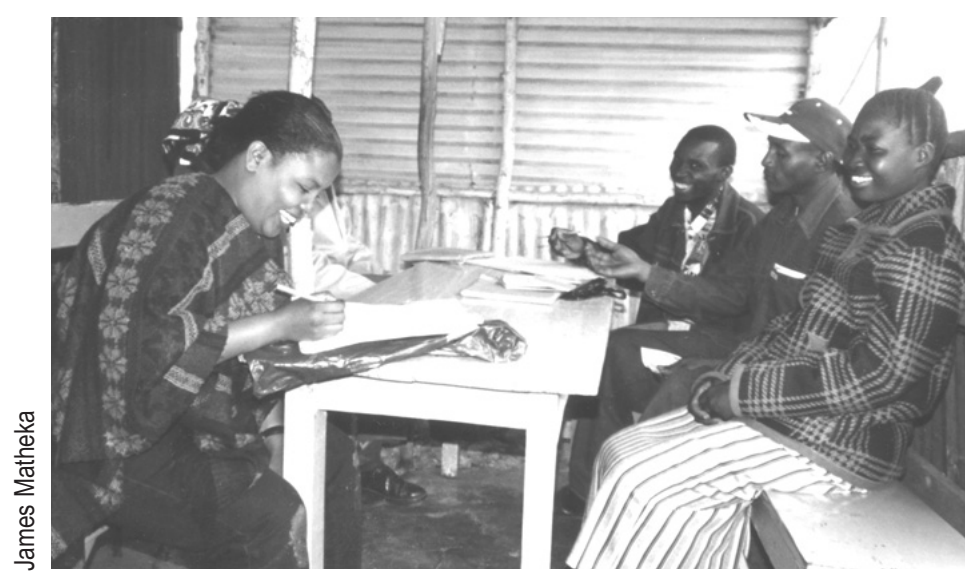

raparigas, foram formados e registados no Ministério da Cultura e Serviços Sociais. No âmbito do maior grupo de 25 , foram formados subgrupos com cinco membros cada um, com designação watano, que em Kiswahili é a palavra que designa cinco.

Os responsáveis oficiais pelo crédito da K-Rep ofereceram seis dias de formação para os membros, abordando questões tais como a gestão de negócio e competências de planeamento, competências empresariais, competências para a vida diária e papéis de género. Os membros "watano" encontravam-se semanalmente, ocasião em que as jovens contribuíam com poupanças para uma conta conjunta que eventualmente constituiria uma garantia para microcréditos. Apesar das contribuições dos membros para a conta de poupança conjunta continuarem ao longo da sua participação, os fundos só poderiam ser levantados quando uma das jovens abandonasse o TRY. Para obter um empréstimo, era pedido a uma participante que traçasse um plano de negócios e efectuasse aplicações relacionadas que eram revistas e acordadas por outros membros do grupo. As jovens recebiam empréstimos faseados; dois membros "watano" recebiam empréstimos iniciais e os restantes membros recebiam empréstimos assim que os seus comembros demonstrassem fiabilidade através de reembolsos semanais e regulares.
Nesta primeira fase, os montantes dos empréstimos iam desde os 40 aos 200 dólares americanos. Os reembolsos tinham início na semana posterior ao desembolso do empréstimo a uma taxa de juro de $15 \%$. As jovens criaram os negócios que escolheram, incluindo salões de cabeleireiro, espaços de restauração, lojas de pequeno comércio e construção de habitações simples para arrendamento.

As jovens participaram activamente na primeira fase do TRY e no início as taxas de liquidação dos empréstimos eram altas. No entanto, com o tempo as taxas de liquidação diminuíram, alguns "watanos" foram dissolvidos e as jovens começaram a abandonar o programa. A primeira fase enfatizou o fornecimento de crédito como a força impulsionadora do TRY, com pouco reconhecimento das necessidades de apoio social das jovens e da importância em terem poupanças seguras e acessíveis como protecção contra situações de emergência. Os colaboradores do programa avaliaram a primeira fase do TRY e traçaram modificações para a segunda fase.

\section{Segunda fase - Fortalecer a componente de apoio social do TRY (2001-2004)}

$\mathrm{O}$ aumento de incumprimentos de pagamentos e de abandonos levou a K-Rep e o Population Council a analisar mais atentamente 0 contexto social da vida dessas jovens. Apenas $12 \%$ das participantes do TRY viviam com ambos os pais. Os restantes viviam noutros contextos vários: com um agregado familiar monoparental, um namorado ou como responsável pelo sustento da sua própria casa. Mais de metade das participantes tinha migrado para Nairobi, em busca principalmente de trabalho e apenas metade declarou ter amigos ou outras pessoas a quem poderiam recorrer para as apoiar. Apenas $37 \%$ das jovens declararam que a sua primeira experiência sexual foi desejada e $24 \%$ declararam que tinham tido relações sexuais em troca de dinheiro, ofertas ou ajuda.

A primeira fase do TRY centrou-se no fornecimento de crédito, mas para muitas das participantes a solidariedade dos grupos representou uma fonte de apoio social e de camaradagem de primeira necessidade. Os colaboradores do programa decidiram alargar 0 apoio social que ofereciam, adicionando um número de mentores adultos para trabalharem em paralelo com os responsáveis pelo crédito. Enquanto a preocupação dos responsáveis pelo crédito da K-Rep se concentrava nos serviços financeiros, os mentores ofereciam apoio social e aconselhamento, organizavam eventos, seminários e visitas guiadas e davam orientações conforme fosse necessário. Nove mentores foram recrutados, com experiência em assistência social, desenvolvimento da comunidade, cuidados de saúde e controlo de pequenos negócios.

Os mentores e responsáveis pelo crédito organizaram seminários nos quais as participantes do TRY puderam receber informações e debater questões com oradores convidados. Foram organizados seminários em larga escala sobre questões como 0 $\mathrm{VIH} / \mathrm{SIDA}$, violência domésticas e violência com base no sexo, direitos das mulheres, abuso de droga e álcool, relacionamentos entre 
homens e mulheres e planeamento familiar. Os seminários sobre 0 $\mathrm{VIH} / \mathrm{SIDA}$ forneceram informações sobre aconselhamento voluntário e testes, nutrição no tratamento do $\mathrm{VIH}$, transmissão de mãe para filho e terapia anti-retroviral.

Inicialmente, as jovens responderam com entusiasmo aos mentores, assumindo a sua presença como prova de que a K-Rep demonstrou o seu interesse em fornecer mais do que a prestação de serviços financeiros. No se auge, o TRY contava com mais de 500 membros na segunda fase. Apesar disso, as jovens continuaram a abandonar o programa, em grande parte porque temiam pela segurança das suas poupanças, especialmente quando os comembros faltavam com os empréstimos. Outro dos principais motivos pelo qual as jovens declaravam que abandonavam o programa devia-se a não poderem aceder rapidamente às suas poupanças em situações de emergência essencialmente porque estas eram retidas como garantias para o grupo. Por outro lado, apesar da maioria das jovens ter dado importância aos encontros em grupo e ter ganho amizades, muitas não estavam interessadas nos empréstimos contínuos que o programa enfatizava. Por conseguinte, os gestores do programa traçaram um plano para oferecer às jovens poupanças seguras e acessíveis juntamente com uma interacção segura e de apoio dos grupos de pares.

\section{Terceira fase - Formar os Young Savers Clubs e proporcionar espaços seguros (2004 - presente)}

Em 2004, os gestores do programa TRY formaram os Young Savers Clubs (Clubes de Poupanças para Jovens) que funcionavam independentemente dos grupos de crédito e poupança do TRY. Os Young Savers foram recrutados através dos membros do TRY, responsáveis de crédito, mentores e outros membros da comunidade, tais como assistentes sociais. Tal como no TRY, os membros dos Young Savers Clubs juntaram-se em grupos de 20 a 25 membros e levaram a cabo encontros semanais conduzidos por um responsável de crédito ou um mentor. Nos finais de 2004, 123 mulheres jovens tinham-se tornado membros e contribuíam com as suas poupanças, mesmo não o fazendo numa base regular.

Os membros do clube depositam as suas poupanças junto de um tesoureiro, através do sistema de cadernetas de poupança. Os clubes realizam debates semanais, encontros com mentores e

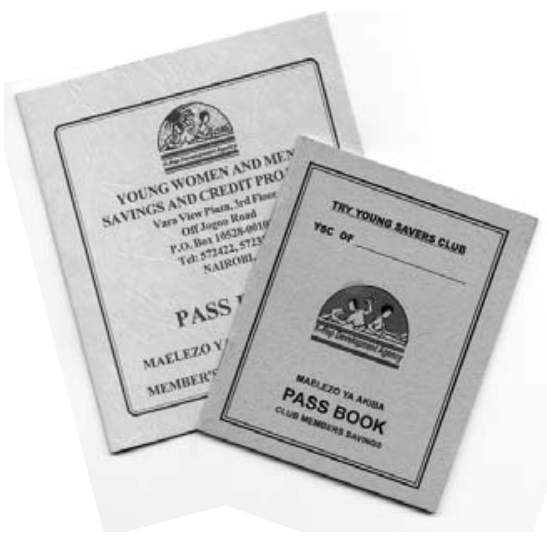

participam em actividades desportivas e jogos. 0 dinheiro de todos os grupos de poupança é mantido numa conta singular em nome da K-Rep. Se uma participante desejar levantar dinheiro, preenche um impresso para levantamento e recebe-o na semana seguinte. As jovens apreciam poder guardar o seu dinheiro num local seguro e muitas delas referem que o grupo as ajuda a serem disciplinadas das questões relacionadas com dinheiro. Tal como nos grupos do TRY, as jovens do Young Savers Clubs também apreciam a amizade que criaram.

Tentei [poupar dinheiro] em casa muitas vezes, mas vejo alguma coisa como sapatos, parto o mealheiro e gasto-o [o dinheiro]. Com o Young Savers, o dinheiro está seguro porque está no banco. Não pode ser transferido para outra pessoa qualquer, como o meu marido quando vê alguma coisa que quer comprar com o meu dinheiro.

- 19 anos de idade, casada, sem filhos e nove anos de escolaridade

Do que eu gostei, além da poupança, foi dos seminários. Gosto sobretudo da maneira como somos ensinadas a gerir o nosso negócio, a alimentação e como manter a forma. Praticamos exercício durante cerca de 20 minutos. Também preenche os momentos em que estou desocupada. No grupo, os problemas - mesmo os problemas pessoais - tornam-se menos preocupantes quando os partilhamos.

- 20 anos de idade, casada, um filho e oito anos de escolaridade

O Young Savers Club oferece meios de vida e oportunidades de apoio social às jovens sem a pressão associada com empréstimos e reembolsos. Quando a alternativa das poupanças voluntárias foi também oferecida aos utentes dos groups do TRY, quase todas juntarem ao Young Savers mantendo simultaneamente a sua afiliação no TRY, demonstrando a importância das poupanças seguras e acessíveis para as raparigas e mulheres jovens.

\section{Avaliação do programa TRY}

O impacto do programa TRY foi avaliado por um estudo longitudinal de participantes com um grupo comparativo identificado através de estudos transversais com base em comunidades, levados a cabo como ponto de partida e de chegada (Erulkar e Chong 2005). As participantes do TRY foram entrevistadas quando ingressaram e abandonaram o programa. Cada participante foi comparada com uma pessoa de controlo aproximadamente da mesma idade, nível escolar, estado civil, estado de maternidade e situação de trabalho que vivia na mesma área de residência. A comparação das participantes e das suas pessoas de controlo permitiram aos investigadores avaliar as mudanças entre as participantes do TRY que pudessem estar associadas às actividades do programa. No total, 326 participantes e as suas pessoas de controlo foram entrevistadas no início e 222 pares foram entrevistados no fim.

Os investigadores compararam as participantes do TRY com as suas pessoas de controlo correspondentes com base em indicadores económicos e financeiros; atitudes sobre os papéis do género; e conhecimentos, comportamento e negociação sobre saúde reprodutiva. Apesar desses dois grupos terem tido rendimen- 
tos semelhantes no nível inicial, no nível final as jovens que participaram atingiam níveis de rendimentos significativamente mais elevados que as que não participaram. Da mesma forma, apesar dos seus rendimentos familiares serem semelhantes na fase inicial, na fase final os rendimentos das participantes do TRY eram consideravelmente mais elevados que as que não participaram. As participantes do TRY tinham significativamente mais poupanças e estavam mais receptivas a guardar as suas poupanças num local seguro, em comparação com as que não participaram que estavam mais receptivas a guardá-las em casa onde corriam o risco de ser roubadas ou confiscadas pelos pais, tutores ou maridos. As jovens que participaram no TRY também demonstraram um comportamento mais liberal que as que não participaram face aos papéis dos género. Apesar dos seus conhecimentos de saúde reprodutiva não serem muito elevados, o estudo indicou que as jovens participantes do TRY tinham uma capacidade acrescida para recusar relações sexuais indesejáveis e teriam insistido no uso do preservativo em comparação aos grupos de controlo. As limitações do estudo foram a baixa taxa de respostas na fase final, $68 \%$, e problemas de controlo para selecção das participantes do TRY.

\section{Planear diferentes condições e capacidades crescentes}

A experiência do TRY enfatizou a vulnerabilidade das raparigas e mulheres jovens nas áreas urbanas de Nairobi e realçou a sua diversidade apesar de residirem nos mesmos bairros pobres urbanos. Também realçou as diferentes capacidades das jovens durante a sua transição para a idade adulta. 0 modelo inicial do microcrédito foi apropriado apenas para um pequeno grupo de raparigas e mulheres jovens mais aptas e menos vulneráveis. Para a maioria das mulheres jovens, o empreendorismo e os empréstimos consecutivos não eram uma preocupação de primeira ordem. Em vez disso, as suas necessidades fundamentais estavam relacionadas com a aquisição de capital social (incluindo o acesso a grupos de apoio e mentores), a manutenção da segurança física e a oportunidade de poupar o seu dinheiro num local seguro e acessível. Quando estas necessidades eram atendidas, o empreendorismo e a utilização das oportunidades de crédito podiam seguir-se-lhe.

Uma estrutura de grupo fiável e segura deve ser o centro de futuros programas para as jovens vulneráveis, sendo a participação entendida como uma experiência positiva. As jovens mais vulneráveis necessitam de um local além das suas famílias para inter- acção com pares, intervenção em caso de crise, protecção das suas poupanças e desenvolvimento de competências básicas para meios de vida. Só quando tais elementos fundamentais do capital social estão apostos, é que as jovens estarão aptas a tirar proveito de alternativas económicas mais amplas.

Recomenda-se uma abordagem orientada para os programas de meios de vida que tome em consideração as capacidades crescentes e vulnerabilidades das jovens e mulheres jovens. Programas de nível inicial que oferecem locais seguros, competências para meios de vida, "educação financeira" e poupanças pessoais poderão servir como "incubadoras" e preparar as jovens para oportunidades mais exigentes. Quando se sentirem preparadas, as jovens poderão decidir ingressar em programas de poupança orientados por objectivos, formação profissional e de desenvolvimento de competências empresariais e, numa fase posterior, o microcrédito e outros serviços financeiros. Tal modelo orientado permite (na teoria) às jovens encontrarem apoio social sem terem que assumir compromissos de desempenho, ingressarem em actividades a nível inicial e com o tempo escolherem o seu nível de risco assim que ficam totalmente preparadas para aceder a alternativas mais exigentes.

\section{Referências}

African Population and Health Research Center (APHRC). 2002. Population and Health Dynamics in Nairobi's Informal Settlements. Nairobi: APHRC.

Central Bureau of Statistics (CBS), Ministry of Health (MOH), and ORC Macro. 2004. Kenya Demographic and Health Survey 2003. Nairobi and Calverton, MD: CBS, MOH, and ORC Macro.

Erulkar, Annabel and Erica Chong. 2005. "Evaluation of a Savings and Micro-Credit Program for Vulnerable Young Women in Nairobi." New York: Population Council.

Erulkar, Annabel, Judith Bruce, Aleke Dondo, Jennefer Sebstad, James Matheka, Arjmand Banu Khan, and Ann Gathuku. 2006. Tap and Reposition Youth (TRY): Providing Social Support, Savings, and Micro-Credit Opportunities for Young Women in Areas with High HIV Prevalence. SEEDS No. 23. New York: Population Council.

Zulu, Eliya, Alex Chika Ezeh, and F. Dodoo. 2000. "Slum Residence and Sexual Outcomes: Early Findings of Causal Linkages in Nairobi, Kenya." African Population and Health Research Center Working Paper No. 17. Nairobi: APHRC.

\section{Doadores}

Ford Foundation, DFID (the UK Department for International Development), the William $\mathrm{H}$. Kaufman Charitable Foundation, the

Para mais informações ou fotocópias de outros sumários nestas séries, contacte publications@popcouncil.org Para recursos adicionais, consulte www.popcouncil.org/pgy

Population Council

One Dag Hammarskjold Plaza

Nova lorque, NY 10017 E.U.A.

(c) 2006 The Population Council, Inc. 